\title{
Synoptic Classes as a Predictor of Hourly Surface Wind Regimes: The Case of the Central and Southern Israeli Coastal Plains ${ }^{\mathbb{O}}$
}

\author{
SigALIT BERKOVIC \\ Department of Mathematics, Israel Institute for Biological Research, Ness Ziona, Israel
}

(Manuscript received 25 February 2016, in final form 4 April 2016)

\begin{abstract}
This work considers whether it is possible to use semiobjective synoptic classes as a year-round predictor of hourly surface winds in Israel. Previous literature has quantitatively characterized the hourly surface flow during the summer under a single synoptic group — the Persian trough—but no quantitative verification has been made for the other seasons. This study undertook a statistical characterization of the surface winds under frequent synoptic classes. The calculated statistical parameters were averages, standard deviations, steadiness, and statistical significance, determined using measurements from 12 weather stations of the Israel Meteorological Service. High steadiness of the surface wind field was found for a significant number of hours. The verification of the characterization at 0000 UTC by two calculations, the first according to the class defined at the previous 1200 UTC and the second according to the next 1200 UTC, showed similar results. Therefore, the synoptic class can be used as a predictor of hourly surface winds during the entire year. These statistical results provide an automatic prediction of the hourly surface wind average and standard deviation according to synoptic class. They may aid in risk assessment or statistical downscaling of seasonal or monthly winds. Such applications can be employed in other parts of Israel. Typical values for hours at which steady flow was obtained are as follows: steadiness $>0.65$, wind direction standard deviation $<60^{\circ}$, wind speed standard deviation of $1-2 \mathrm{~m} \mathrm{~s}^{-1}$, and sector direction widths of $50^{\circ}-150^{\circ}$, within $70 \%$ statistical significance.
\end{abstract}

\section{Introduction}

The connection between synoptic and mesoscale flow around the world has been studied using various approaches, starting with studies on the influence of the large-scale flow on sea-breeze evolution (Gilliam et al. 2004) and on the statistical averaging of wind speed and direction for specific months or synoptic classes (Kassomenos et al. 1998; Guardans and Palomino 1995; Maheras et al. 2000) and ending with more rigorous methods, such as principal component analysis, selforganizing maps, and cluster analysis, to conjugate synoptic classes with surface wind variability (Jimenez et al. 2009; Beaver and Palazoglu 2006; Conil and Hall 2006; Nigro and Cassano 2014). Because air pollution is

Supplemental information related to this paper is available at the Journals Online website: http://dx.doi.org/10.1175/ JAMC-D-16-0093.s1.

Corresponding author address: Sigalit Berkovic, P.O.B. 19, Ness Ziona 7410001, Israel.

E-mail: berkovic@iibr.gov.il strongly related to diurnal wind flow, including recirculation along the shore of seas or lakes, many authors (Kallos et al. 1993; Pakalapati et al. 2009; Beaver et al. 2010; Ngan and Byun 2011; Pearce et al. 2011) have studied the connection between air pollution and synoptic and mesoscale weather conditions.

In Israel, the only semiobjective synoptic classification for a year-long period was created by Alpert et al. (2004). A description of this classification is given in section 2. It has been employed to study dust, the climatological aspects of cyclones, air pollution, and spatial rain distribution (Ganor et al. 2010; Saaroni et al. 2010a,b; Rostkier-Edelstein et al. 2015) but has not been used at an hourly resolution.

Qualitative descriptions of surface wind as a function of synoptic class have been given by Levy et al. (2008), Ziv and Yair (1994), and Goldreich (2003). Typical surface flow under the influence of the various synoptic groups is described in section 2 .

Publisher's Note: This article was revised on 27 July 2016 to correct editing errors in the column headers of Table 2. 
Israel is situated on the eastern coast of the Mediterranean Sea. The coastal plain is relatively flat, with a width varying from $\sim 10 \mathrm{~km}$ near Tel Aviv to $\sim 50 \mathrm{~km}$ in the south (Beersheba). The mountains of Judea and Samaria are parallel to the shore; the mountain ridge, with peaks $800-1200 \mathrm{~m}$ above mean sea level (MSL), extends from north to south.

The mesoscale flow in the Israeli coastal and interior plains is derived from the terrain's inhomogeneity (which includes the land-sea contrast, urban heat islands, features of the coastline, and the proximity of mountains to the coast). These parameters dictate sea-land breezes and upslope-downslope circulations (Doron and Neumann 1977; Goldreich et al. 1986). Along the coastal and the interior plains, the wind is southwest-northwest during daylight hours and northeast-southeast during the night. The synoptic classes have specific pressure gradients, each affecting the local wind.

One of the manifestations of breeze flow is coastal recirculation, which refers to the return of air masses to their source region as a result of a change from a land breeze to a sea breeze. Coastal recirculation has been shown to have an adverse effect on air-pollutant concentrations in many regions around the world. Levy et al. $(2008,2010)$ studied the coastal recirculation from five years of data at stations along the Israeli coast. The recirculation is dominant under weak synoptic forcing, when the surface flow is dictated by mesoscale effects. During the spring, the high frequency of transitional days from cold events (such as frontal lows) to hot and dry events [due to the Red Sea trough (RST), winter highs, or Sharav lows (SL)] enhances the land-sea-breeze effect and, therefore, increases the intensity of recirculation. Strong synoptic forcing, resulting in low recirculation, was found for these synoptic groups: Persian troughs (PT), deep winter lows, and winter highs. [The classes related to these groups include the deep Cyprus low from the north $\left(\mathrm{CL}_{N}-\mathrm{D}\right)$, the deep low from the east $\left(\mathrm{L}_{\mathrm{E}}-\mathrm{D}\right)$, the high from the north $\left(\mathrm{H}_{\mathrm{N}}\right)$, and the high from the east $\left(\mathrm{H}_{\mathrm{E}}\right)$. These classes will be discussed in the next sections.]

Studies on the effect of synoptic flow on sea-breeze circulation (Gilliam et al. 2004; Zhong and Takle 1993) show that enhancement occurs when the synoptic wind and the sea-breeze wind are aligned in the same direction. Offshore flow has the opposite effect since the synoptic wind is aligned in the opposite direction to the sea breeze. Strong offshore flow $\left(>5 \mathrm{~m} \mathrm{~s}^{-1}\right)$ completely eliminates the sea breeze. Ambient flow parallel to the coastline (i.e., the synoptic wind is orthogonal to the sea breeze) presents an intermediate sea-breeze evolution relative to the onshore and offshore cases.

Utilizing a dense net of measurements, Skibin and Hod (1979) quantitatively summarized the three-hourly surface winds in northern Israel during July. Their work presents the surface wind regimes during the summer under the influence of a single synoptic group: the PT.

No previous attempt has been made to quantitatively characterize wind regimes across Israel over an entire year. As a first step toward this goal, we tested the synoptic classes formulated by Alpert et al. (2004) as a predictor of hourly surface wind regimes during the year. The regimes were determined by calculating statistical parameters for each frequent synoptic class. The data were taken from Israel Meteorological Service (IMS) measurements at 12 weather stations from 2007 to 2013.

Section 2 describes the synoptic groups and classes in the eastern Mediterranean (EM) Sea region as defined by Alpert et al. (2004). Section 3 displays the locations of the stations and defines the statistical parameters used. Section 4 discusses the variability of the synoptic parameters during the day and examines the connections between steady surface flow patterns and synoptic classes. Section 5 summarizes and concludes the study.

\section{EM synoptic groups and classes}

There are two main seasons in the EM (Fig. 1) - the dry season in summer (mid-June-September) and the wet season in winter (December-February) — as well as the "transition months" (April-May and OctoberNovember). Five synoptic groups characterize this climate (Ziv and Yair 1994; Alpert et al. 2004; Osetinsky 2006). A single group is dominant during the summer, and four groups prevail during the winter and the transition months. Figure 2 displays sea level pressure (SLP) maps over the EM area for typical days for each of the 14 classes derived from the four most frequent synoptic groups (Osetinsky 2006).

1) The PT is a persistent synoptic class during the summer months (mid-June-September). This trough extends from the Asian monsoon through the Persian Gulf along southern Turkey and the Aegean Sea (Fig. 2, bottom row). During the summer, the depth of the PT changes. Deep troughs reach Greece, and shallow troughs do not reach the Mediterranean Sea. Because of mid- to upper-level subsidence created by the subtropical high there is practically no rain during the summer (Ziv et al. 2004; Goldreich 2003). A remarkable daily periodicity is obtained in the EM during the summer. Because the synoptic situation is static, the flow over the area is mainly determined by mesoscale and microscale processes. Northwesterly synoptic winds flow over the EM as a result of the PT and the northwest etesian winds (Ziv et al. 2004; Poupkou 


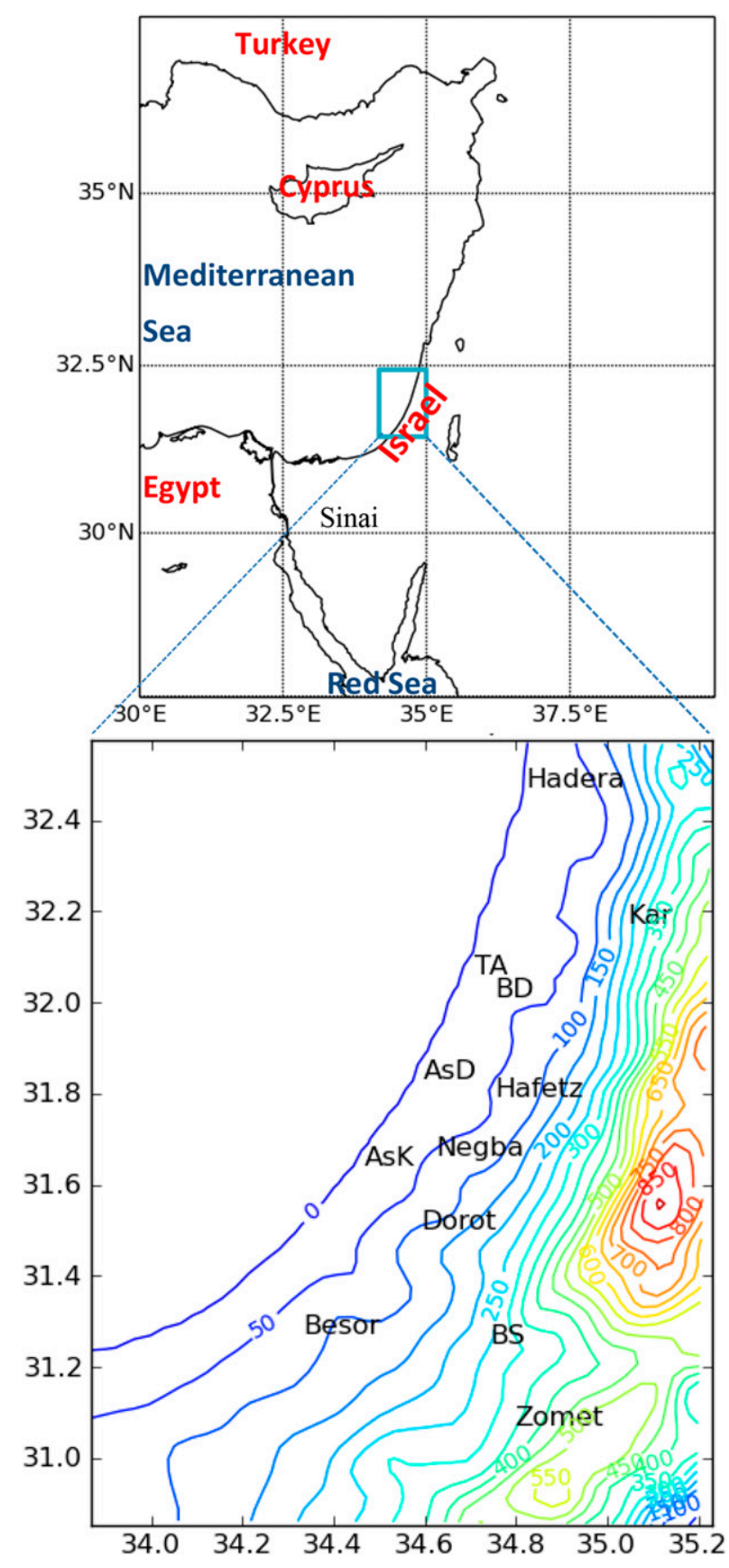

FIG. 1. The EM and the studied area: shown are Tel Aviv (TA; altitude $10 \mathrm{~m}$ ), Beit Dagan (BD; $31 \mathrm{~m}$ ), Karnei Shomron (Kar; $330 \mathrm{~m}$ ), Ashdod (AsD; $5 \mathrm{~m}$ ), Ashkelon (AsK; 5 m), Hafetz Hayim (Hafetz; $80 \mathrm{~m}$ ), Beersheba (BS; 279 m), Zomet HaNegev (Zomet; $360 \mathrm{~m})$, and Besor $(110 \mathrm{~m})$. On the right are the mountains of Judea and Samaria. On the left is the Mediterranean Sea. The colored contours show the terrain height $(\mathrm{m})$.

et al. 2011; Tyrlis and Lelieveld 2013; Tyrlis et al. 2013). During early-morning hours, when the temperature gradient between air and sea is minimal, the synoptic wind is mostly manifested as west-southwest winds.
2) The winter lows (L) and Cyprus lows (CL) form the dominant synoptic group during winter (Fig. 2, top row). They are responsible for the largest amount of rain in the EM. CLs are the main contribution to the winter lows, each contributing rainfall during twothree consecutive days. The name CL is given to Mediterranean cyclones that reach the EM; they need not be located over Cyprus itself (Lionello 2012) to be designated as CLs. Deep lows are characterized by strong (maximum $\sim 10 \mathrm{~m} \mathrm{~s}^{-1}$ ) westerly winds.

3) Highs come in two types. (i) The "Siberian highs" (winter highs) occur mainly during the cool season. Siberian highs are highs of a northern origin-from Europe (e.g., Romania, Turkey, and Caucasia) or Siberia (the winter Asiatic monsoon) itself. The extension of the Siberian high is rare, occurring once every few years. It is accompanied by cold, dry northeasterly winds that last for several days. Winter highs bring fair weather, inducing cold, dry northerly-easterly winds over Israel (Fig. 2, middle row). (ii) The "subtropical high" [the high to the west of Israel $\left(\mathrm{H}_{\mathrm{W}}\right)$ ] may occur throughout the year. It is an extension of the Azorean high, which prevails over North Africa. When this high is extended farther to the east and reaches Israel, it brings northwest winds with humid air from the sea (Fig. 2, middle row).

4) The RST, a trough over the Red Sea and its surroundings, is an extension of a low over the Sudan, which may occur during the transition months or during winter (Fig. 2, bottom row). It is characterized by a dry easterly flow east of the trough axis (Saaroni et al. 1998). When an upper trough stretches over the EM, the RST develops northward and deepens. As a result, rain clouds may develop. Convective storms may evolve and cause floods over southern Israel and the Sinai, especially with ground heating during the day (Tsvieli and Zangvil 2007).

5) The SLs, which appear mainly during April, propagate from the Sahara to Israel accompanied by hot, dry easterly winds (ahead of the warm front), bringing dust from the Sahara (Saaroni et al. 1998; Ziv and Yair 1994). Events in this group are relatively rare. (Their frequency is fewer than three days per year, and therefore they are not represented in Fig. 2.)

The subdivision of the first four synoptic groups provides the 14 most frequent classes referred to in this work. The divisions are made according to the location/depth and the field gradients of the classes over the EM region.

The CL group includes the following classes: $\mathrm{CL}_{\mathrm{N}}-\mathrm{D}$ and the shallow $\mathrm{CL}$ to the north $\left(\mathrm{CL}_{\mathrm{N}}-\mathrm{S}\right)$. The $\mathrm{L}$ group 
$\mathrm{L}_{\mathrm{E}}-\mathrm{D}(11)$

8.49

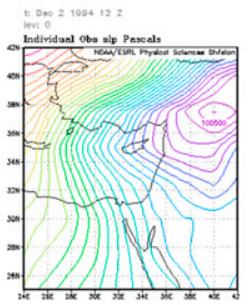

$\mathrm{H}_{\mathrm{E}}(7)$

11.79

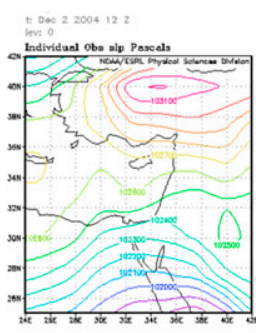

PT-W (4) 52.33

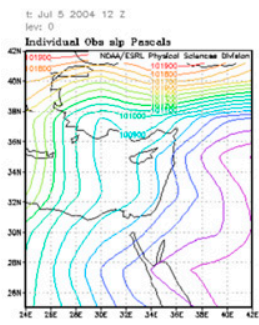

$C L_{N}-\mathrm{D}(14) \quad 9.84$

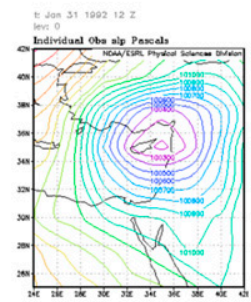

$\mathrm{H}_{\mathrm{N}}(9)$

16.37

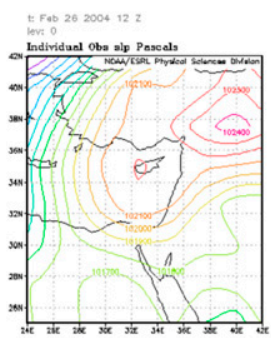

PT-M (5) 53.67

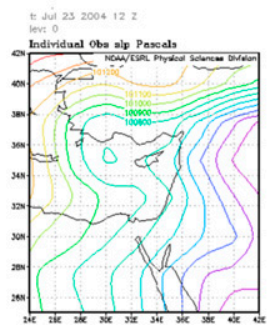

$\mathrm{L}_{\mathrm{W}}(16) \quad 7.95$

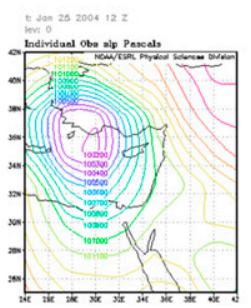

$\mathrm{H}_{\mathrm{W}}(8) \quad 72.37$

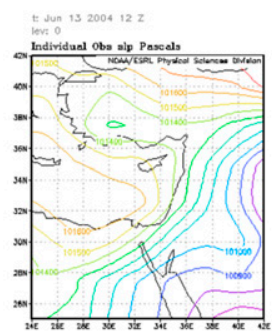

PT-D (6) 7.74

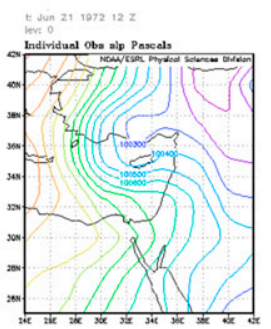

$\mathrm{L}_{\mathrm{E}}-\mathrm{S}(17) \quad 16.81$

$\mathrm{CL}_{\mathrm{N}}-\mathrm{S}(15) 17.04$
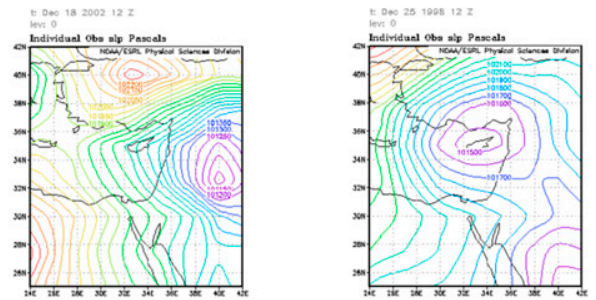

$\mathrm{H}_{\mathrm{C}}(10) \quad 15.67$

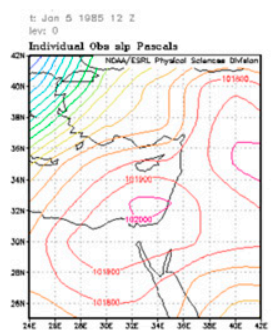

$\mathrm{RST}_{\mathrm{E}}(1) 44.16$

$\mathrm{RST}_{\mathrm{C}}(3) 23.63$

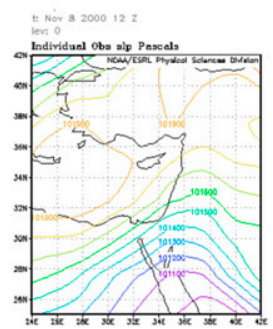

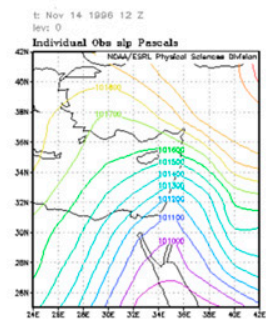

FIG. 2. The EM frequent $\left(>5\right.$ days $\left.\mathrm{yr}^{-1}\right)$ synoptic classes and their numbers as defined by Alpert et al. (2004). Each map is an SLP (Pa) map from a representative day (Osetinsky 2006). The synoptic class number (in parentheses) and the frequency (number of days per year) of each synoptic class are denoted above each SLP map. (top) The winter lows: $\mathrm{L}_{E}-\mathrm{D}, \mathrm{CL}_{\mathrm{N}}-\mathrm{D}, \mathrm{Lw}, \mathrm{L}_{\mathrm{E}}-\mathrm{S}$, and $\mathrm{CL}_{\mathrm{N}}-\mathrm{S}$. (middle) Highs: $\mathrm{H}_{\mathrm{E}}$, $\mathrm{H}_{\mathrm{N}}, \mathrm{H}_{\mathrm{W}}$, and $\mathrm{H}_{\mathrm{C}}$. (bottom) Troughs: PT-W, PT-M, PT-D, RST $\mathrm{E}_{\mathrm{E}}$, and $\mathrm{RST}_{\mathrm{C}}$.

includes these classes: the cold low to the west $\left(\mathrm{L}_{\mathrm{W}}\right)$, $\mathrm{L}_{\mathrm{E}}-\mathrm{D}$, and the shallow low to the east $\left(\mathrm{L}_{\mathrm{E}}-\mathrm{S}\right)$. The RST group includes these classes: the RST with an eastern axis $\left(\mathrm{RST}_{\mathrm{E}}\right)$ and the RST with a central axis $\left(\mathrm{RST}_{\mathrm{C}}\right)$. The location of the axis is defined relative to the EM coastline. PTs are divided into three classes: deep, medium, and shallow (PT-D, PT-M, and PT-W, respectively). Siberian highs (winter highs) are divided into three classes: $\mathrm{H}_{\mathrm{N}}, \mathrm{H}_{\mathrm{E}}$, and the high over Israel $\left(\mathrm{H}_{\mathrm{C}}\right)$. The summer subtropical high is the $\mathrm{H}_{\mathrm{W}}$. The names are based on the location of the pressure gradient.

Alpert et al. (2004) and Osetinsky (2006) designed the synoptic classification using a classical discriminant analysis (DA); therefore, it is semiobjective. The meteorological fields used to define the discriminant functions were $1000-\mathrm{hPa}$ geopotential height, temperature, and horizontal wind components ( $u$ and $v$ ) over the EM region. These fields were defined within a square area of $27.5^{\circ}-37.5^{\circ} \mathrm{N}, 30^{\circ}-40^{\circ} \mathrm{E}$ at $1200 \mathrm{UTC}$ daily. The data were derived from the NCEP-NCAR reanalysis. It was found by Alpert et al. (2004) that the synoptic classification can be made by referring to surface data only $(1000 \mathrm{hPa})$, without the need to include higher pressure levels. Therefore, the $1000-\mathrm{hPa}$ geopotential height is the only relevant pressure characterizing the various synoptic classes. Also, a single hour-1200 UTC —was found to be representative of the 24 -h period.

\section{Method}

The data used for this study were the standard three-hourly measurements of wind at 12 stations of 
the IMS (https://ims.data.gov.il/). The measurements were taken $10 \mathrm{~m}$ above the ground over the course of seven years, from 2007 to 2013 . The data contain 10min averages for every third hour starting from 0000 UTC. Note that the local time (LT) is UTC +2 during winter and UTC +3 during summer. This study uses UTC to be consistent throughout the year. Because of discontinuities in the data, especially during the winter months, it was confirmed that each station took at least 860 measurements during each winter (December-March) of the above years. This verification ensured a sufficient number of data for this study. The IMS measures the wind by wind anemometers. Their reported $10-\mathrm{min}$ averages are rounded to $0.5 \mathrm{~m} \mathrm{~s}^{-1}$ and to $10^{\circ}$ for the wind speed and direction, respectively. All measurements refer to 10 -min averages, with a minimum average wind speed of $0.5 \mathrm{~m} \mathrm{~s}^{-1}$. The stations chosen for this study are situated mainly along the coastal and interior plains. One station (Karnei Shomron) is on the western slope of the Judean mountains, and two others (Beersheba and Zomet HaNegev) are in the northern part of the Negev Desert. The area covering these stations is from Hadera in the north to Zomet HaNegev in the south $(\sim 150 \mathrm{~km})$ and from Besor in the west to Karnei Shomron in the east $(\sim 50 \mathrm{~km})$. The locations of all of these stations are shown in Fig. 1.

The synoptic class of each day in the data above was defined using semiobjective classification. These data were provided by Alpert et al. This work discusses the 14 most frequent synoptic classes, with a frequency of greater than 5 days per year (Osetinsky 2006; see section 2 and Fig. 2). The following statistical parameters were calculated at each available hour (3-h intervals starting at 0000 UTC) at each station. At least 30 hourly measurements were required during the seven years of the study to calculate the various statistical parameters. The lowest number of hourly measurements $(\sim 30)$ was found for the classes PT-D and $\mathrm{L}_{\mathrm{W}}$ (Fig. 2). Each statistical calculation at a certain hour and synoptic class included all of the available measurements over the seven-year period. When calculating hourly averages in this work, we refer to all of the events at a certain hour under a certain synoptic class.

The statistical parameters are averages and standard deviations of surface wind speed and direction, and the steadiness of the surface wind $S$. The wind direction $\theta_{i}$ is a radial variable and therefore will have a different definition in terms of the average and standard deviation. The average zonal and meridional winds $U$ and $V$ are as follows:

$$
\begin{aligned}
& V=\frac{1}{N} \sum_{i=1}^{N}-\mathrm{sp}_{i} \times \cos \left(\theta_{i}\right) \quad \text { and } \\
& U=\frac{1}{N} \sum_{i=1}^{N}-\mathrm{sp}_{i} \times \sin \left(\theta_{i}\right),
\end{aligned}
$$

where wind speed is represented by $\mathrm{sp}_{i}$ and $N$ is the number of observations used. The minimal difference $\Delta_{i}$ between $\theta_{i}$ and the average wind direction $\bar{\theta}$ is defined as

$$
\left|\Delta_{i}\right|=\min \left(\left|\theta_{i}-\bar{\theta}\right|,|2 \pi-| \theta_{i}-\bar{\theta}||\right) .
$$

The standard deviation $\sigma_{\theta}$ of the wind direction is then calculated by the simple two-passes method (Yamartino 1984):

$$
\sigma_{\theta}^{2}=\frac{1}{N} \sum_{i=1}^{N} \Delta_{i}^{2}-\left(\frac{1}{N} \sum_{i=1}^{N} \Delta_{i}\right)^{2} .
$$

The steadiness parameter $S$ (Skibin and Hod 1979; Namboodiri et al. 2012), which is the ratio of the mean wind vector $M_{V}$ and the mean wind speed $M_{\mathrm{sp}}$, is defined as follows:

$$
\begin{aligned}
M_{V} & =\left[\left(\frac{1}{N} \sum_{i=1}^{N} u_{i}\right)^{2}+\left(\frac{1}{N} \sum_{i=1}^{N} v_{i}\right)^{2}\right]^{1 / 2}, \\
M_{\mathrm{sp}} & =\frac{1}{N} \sum_{i=1}^{N}\left(u_{i}^{2}+v_{i}^{2}\right)^{1 / 2}, \quad \text { and } \\
S & =M_{V} / M_{\mathrm{sp}} .
\end{aligned}
$$

Parameter $S$ is equal to 1 when the wind flow is constant. When $S<0.5$, the wind is not steady (Namboodiri et al. 2012; Skibin and Hod 1979).

Since the wind is a vector, two parameters are needed to define its behavior. This study uses $S$ and the standard deviation of wind direction simultaneously to determine the amount of wind steadiness as a function of the synoptic class at each reported hour. Hours at which steady winds occur (hereinafter called "steady hours") were determined. The empirical conditions according to which high steadiness is defined in this study were as follows: average $S$ (over the 12 stations) $>0.65$ and wind direction standard deviation $<60^{\circ}$ for 8 of the 12 stations. These values were derived by trial and error; the $S$ cutoff was changed to obtain the cutoff of the direction standard deviations. Inspection of all statistical parameters at all stations showed high directionality of the wind field for $S$ values $>0.65$. An example is given in section 4c (Fig. 5, described in more detail below). The sector direction widths within $70 \%$ statistical significance $(\mathrm{SD} 70)$ at the various stations (i.e., $70 \%$ of the 
events have wind direction in the sector $\bar{\theta} \pm \mathrm{SD} 70 / 2$, where $\bar{\theta}$ is the average wind direction) were calculated to verify that the standard deviation of the wind direction is representative.

\section{Results}

\section{a. The synoptic parameters at the synoptic hours}

This study verifies whether the synoptic class at 1200 UTC is a predictor for the hourly surface wind. In practice, the synoptic class at 1200 UTC is not necessarily identical to those at 0000, 0600, and 1800 UTC; however, because of the slow rate of synoptic changes, similarities may occur between the $1000-\mathrm{hPa}$ geopotential-height surfaces. This similarity was verified by inspection and calculation of averages and standard deviations at each synoptic hour according to the NCEP-NCAR data taken from Kalnay et al. (1996; http://www.esrl.noaa.gov/psd/data/gridded/data.ncep. reanalysis.html).

The synoptic class is subjectively determined by inspection of the pressure contours. Inspection of $1000-\mathrm{hPa}$ geopotential-height maps from 1985 reveals resemblance (of pressure-contour features) between the 0600, 1200, and 1800 UTC geopotential-height maps (except under SLs, which were not included in this study) during most days. (This includes $75 \%$ of the days during April, $75 \%$ during May-mostly due to SLs-and $85 \%$ during October, November, and January. The frequencies were determined by counting the number of days with similar pressure-contour features in each month.) Less resemblance was found between 0000, 0600, 1200, and 1800 UTC and the next 0000 UTC (referred to as five hours) geopotential-height maps. During April (50\%) and May (65\%), the transition of highs, shallow lows, and SLs reduced the resemblance between the geopotentialheight surfaces and the synoptic winds during the day. During October (85\%), November (70\%), and January $(75 \%)$, the resemblance between the "five hours" increases because the number of fast synoptic changes was reduced (see Figs. S1-S4 in the online supplementary material: Figs. S3 and S4 display poor resemblance). The highest resemblance was obtained during the summer under PTs. Two independent inspections of the data indicated $15 \%$ uncertainty of the above frequencies (3-4 of 30 days).

The average and standard deviation of each synoptic hour were calculated. A comparison of the four geopotentialheight averages of each synoptic hour under each synoptic class from 2007 to 2013 for the NCEP-NCAR data shows a similar average (see also Figs. S5-S8 of the online supplementary material). The differences between the average maps $(\sim 10 \mathrm{~m})$ were smaller than that of the standard deviations $(20-40 \mathrm{~m}$; see the online supplementary material). Therefore, on average, the features of the pressure gradients at each synoptic hour under each frequent synoptic class, except $\mathrm{CL}_{\mathrm{N}^{-}} \mathrm{S}$ and $\mathrm{L}_{\mathrm{E}}-\mathrm{S}$, were similar. Similar calculation of the average $u$ and $v$ components presents a difference of $2 \mathrm{~m} \mathrm{~s}^{-1}$ and $45^{\circ}$ between the average speed and wind direction of the synoptic hours under the frequent synoptic classes $\mathrm{RST}_{\mathrm{E}}, \mathrm{RST}_{\mathrm{C}}, \mathrm{PTs}, \mathrm{L}_{\mathrm{E}}-\mathrm{D}, \mathrm{CL}_{\mathrm{N}}-\mathrm{D}, \mathrm{CL}_{\mathrm{N}}-\mathrm{S}$, and $\mathrm{L}_{\mathrm{E}}-\mathrm{S}$ and the classes of the $\mathrm{H}$ group.

Because synoptic classes are defined at 1200 UTC, 0000 UTC is between two synoptic classes that are not necessarily identical. A comparison of the two average steady-wind fields of the frequent classes, the first according to the previous 1200 UTC and the second according to the next 1200 UTC, was performed. The similarity between the two calculations under each class was determined according to four criteria: 1) the difference between the SD70s is less than $20^{\circ}$ at 11 of the 12 stations, 2) the difference between the $S$ values is less than $0.2,3$ ) the absolute value of the difference between the average direction/speed is less than 1.5 times the standard deviation of the direction/speed (at each station, two standard deviations are calculated, and the standard deviation is defined according to the smaller value), and 4) the absolute value of the difference between the speed/direction standard deviations is less than one-half of the standard deviation according to the narrower distribution.

The comparison at 0000 UTC showed agreement between the two calculations, except under $\mathrm{L}_{\mathrm{W}}$, which proves it is possible to characterize the average surface wind field at 0000 UTC, with the exception of $\mathrm{L}_{\mathrm{W}}$. The synoptic changes from 0000 UTC to the previous 1200 UTC or the next 1200 UTC maintain a similar correlation because of slow synoptic changes.

The differences under $\mathrm{L}_{\mathrm{W}}$ between the SD70s at all the stations were less than $100^{\circ}$; therefore, this class will not be characterized at 0000 and 0300 UTC. SD70s according to the previous 1200 UTC class were less than $190^{\circ}$, and SD70s according to the next 1200 UTC were less than $90^{\circ}$ (i.e., higher steadiness is obtained when the low approaches Israel). Winter lows move eastward with a typical velocity of $\sim 5 \mathrm{~m} \mathrm{~s}^{-1}$ and a radius of $\sim 800 \mathrm{~km}$ (Alpert and Ziv 1989). An estimation of the rate of change of the wind direction $\partial \beta / \partial t$ is calculated by the equation

$$
\frac{\partial \beta}{\partial t}=\frac{-C}{R} \cos \gamma
$$

(Holton 2004), where $C \approx 5 \mathrm{~m} \mathrm{~s}^{-1}, R \approx 800 \mathrm{~km}$, and $\gamma$ is the angle between the streamlines and the direction of motion. It assumes an idealized circular pattern of 

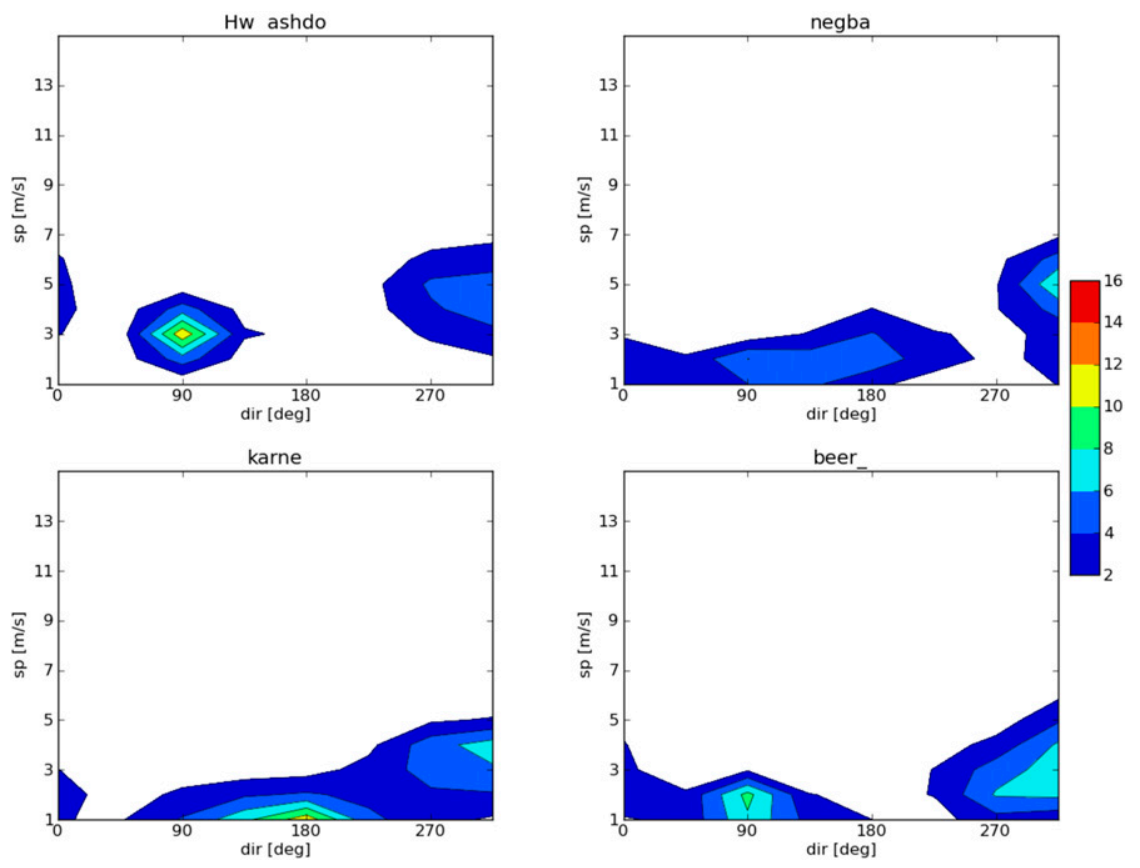

FIG. 3. Diurnal wind histograms at Ashdod (ashdo), Negba (negba), Karnei Shomron (karne), and Beersheba (beer_) under $\mathrm{H}_{\mathrm{W}}$. The color bar indicates the frequency of events (\%).

height contours moving at constant velocity $C$ so that the turning of the wind is due to the motion of the low. It gave an $\sim 30^{\circ}$ direction change during $24 \mathrm{~h}$ for a point situated south of the center of the low $\left(\gamma=0^{\circ}\right.$; the location of Israel relative to the low, according to typical synoptic maps). The direction change explains the low variability of the SD70s under deep lows. Because $\mathrm{L}_{\mathrm{W}}$ is associated with shallow lows, larger SD70s might result from the reduced synoptic effect.

\section{$b$. The effect of the synoptic classes on the diurnal flow}

Surface wind histograms for each synoptic class at each station show the characteristics of the diurnal flow. These histograms display the frequency of events as a function of wind speed and direction. The bin resolution is $45^{\circ}$ for the wind direction and $1 \mathrm{~m} \mathrm{~s}^{-1}$ for the wind speed. The frequency presented in the histograms is higher than $2 \%$. At most of the stations, the most frequent wind directions are similar under each class. Stations that are distant from the coastline have lower wind speed because of the friction over the land. The highest difference between the histograms of the various stations is obtained under $\mathrm{H}_{\mathrm{C}}, \mathrm{H}_{\mathrm{W}}, \mathrm{CL}_{\mathrm{N}}-\mathrm{S}, \mathrm{L}_{\mathrm{E}}-\mathrm{S}$, and $\mathrm{L}_{\mathrm{W}}$. Figures 3 and 4 show examples of histograms at four representative stations (Ashdod, Karnei Shomron, Negba, and Beersheba) under $\mathrm{L}_{\mathrm{E}}-\mathrm{D}$ and $\mathrm{H}_{\mathrm{W}}$. Under $\mathrm{L}_{\mathrm{E}}-\mathrm{D}$, high variability of wind speed is displayed; under $\mathrm{H}_{\mathrm{W}}$, the most frequent wind direction varies widely among the four stations. When the synoptic forcing decreases, the sea-land breeze and upslopedownslope winds have an enhanced effect on the flow, and, therefore, a greater spread of wind directions is obtained.

From inspection of the histograms under all synoptic classes, three main features were found:

1) South-west winds are dominant under deep lows.

2) North-east winds are dominant under RSTs and winter highs.

3) PTs, $H_{W}$, and other shallow synoptic classes show a bimodal distribution, with high frequencies in the sectors east-south and north-west.

Further separation into daytime $(0900,1200$, and 1500 UTC) and night (2100, 0000, and 0300 UTC) surface wind histograms strongly exhibits the features of the diurnal cycle. The most frequent sector of the PTs, $\mathrm{H}_{\mathrm{W}}, \mathrm{H}_{\mathrm{C}}, \mathrm{RST}_{\mathrm{E}}$, and $\mathrm{CL}_{\mathrm{N}}-\mathrm{S}$ daytime histograms is westnorth. The most frequent sector of the daytime histograms for the deep winter lows $\left(\mathrm{L}_{\mathrm{E}}-\mathrm{D}\right.$ and $\left.\mathrm{CL}_{\mathrm{N}}-\mathrm{D}\right)$ is south-west. The RST, $\mathrm{H}_{\mathrm{E}}, \mathrm{H}_{\mathrm{N}}, \mathrm{H}_{\mathrm{C}}$, and $\mathrm{L}_{\mathrm{W}}$ night histograms have a single most frequent sector (east-south) in agreement with the fact that the synoptic winds have an eastern wind component under $\mathrm{RST}_{\mathrm{C}}, \mathrm{H}_{\mathrm{E}}$, and $\mathrm{H}_{\mathrm{N}}$. The interaction of the local circulation and the synoptic wind was described by Levy et al. (2008). Similar conclusions about the effect of synoptic wind on mesoscale flow in a valley were presented by Guardans and Palomino (1995). Because synoptic classes belonging to 

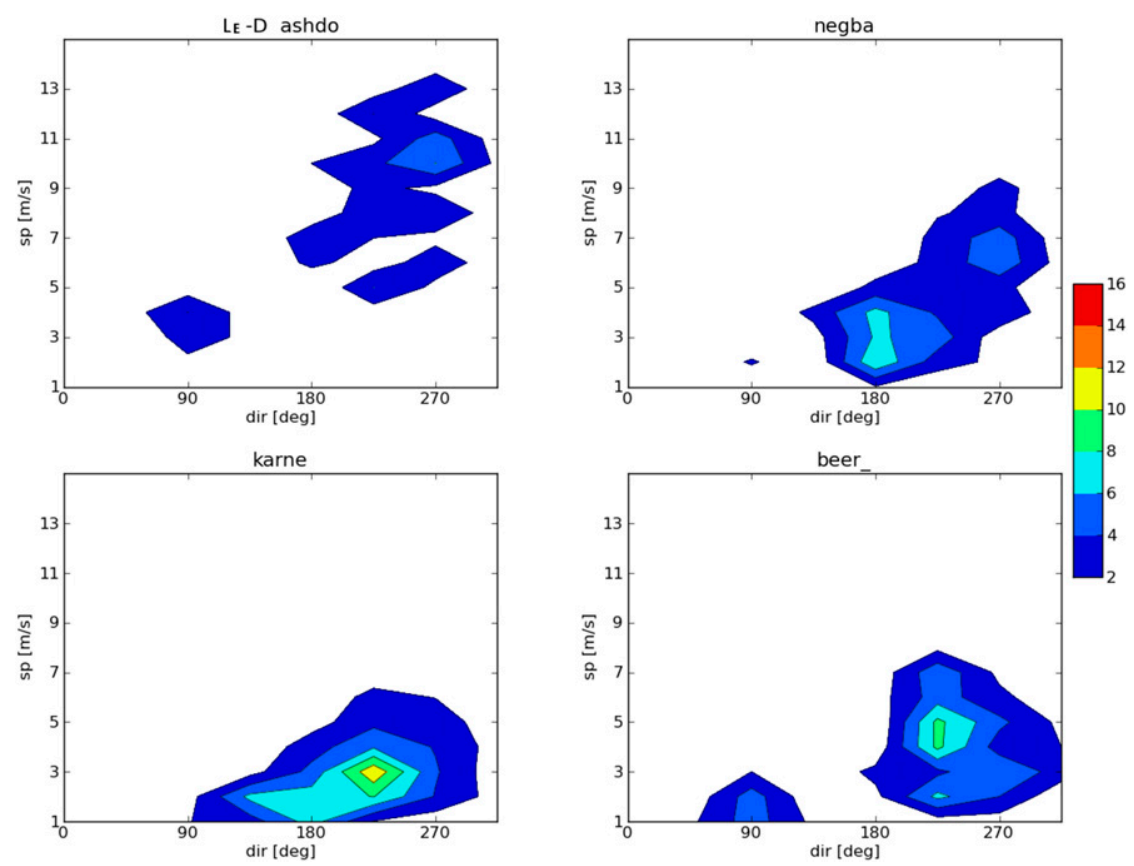

FIG. 4. As in Fig. 3, but under $\mathrm{L}_{\mathrm{E}}-\mathrm{D}$.

the same group (RSTs or $\mathrm{H}_{\mathrm{N}}$ and $\mathrm{H}_{\mathrm{E}}$ ) have similar pressure gradient and contours (e.g., RSTs and $\mathrm{H}_{\mathrm{N}}$ and $\mathrm{H}_{\mathrm{E}}$ ), the histograms are not sensitive to the exact classification of the synoptic class.

\section{c. Determining hourly steady flows as a function of synoptic class}

Steadiness, average, and standard deviation of surface wind were calculated for each station to verify the steadiness of the hourly flow under each synoptic class. Figure 5 is an example of the statistical results obtained for $\mathrm{H}_{\mathrm{E}}$. At 0000, 0300, 0600, 1800, and $2100 \mathrm{UTC}$, high $S$ values $(S>0.65)$ and low direction standard deviation values $\left(<60^{\circ}\right)$ were obtained. The statistical results of all of the synoptic classes lead to the following conclusions:

- Steady winds occurred for a significant number of hours. The steady hours are summarized in Table 1.

- For most of the classes (12 of 14), a similar average wind direction was obtained at all of the stations $\left(\sim 45^{\circ}\right.$ difference between the various directions). The high similarity is due to the geographical proximity of the stations. The dominant wind direction at each steady hour is designated in Table 1.

- The speed standard deviation at the steady hours was $0.5-2.5 \mathrm{~m} \mathrm{~s}^{-1}$. The maximum average speed $\left(10 \mathrm{~m} \mathrm{~s}^{-1}\right)$ and maximum standard deviation speed $\left(2-4 \mathrm{~m} \mathrm{~s}^{-1}\right)$ were obtained for the deep winter lows $\mathrm{L}_{\mathrm{E}}-\mathrm{D}$ and $\mathrm{CL}_{\mathrm{N}}-\mathrm{D}$. The wind speed standard deviation increases as the wind speed increases (i.e., the certainty of wind speed decreases as the wind speed increases).

- The synoptic effect is proportional to the size and location of the pressure gradient. Table 1 displays the effect of the synoptic class on the mesoscale flow. From this table, four categories can be derived:

1) The winter lows $\left(\mathrm{L}_{\mathrm{E}}-\mathrm{D}, \mathrm{CL}_{\mathrm{N}}-\mathrm{D}, \mathrm{L}_{\mathrm{W}}, \mathrm{L}_{\mathrm{E}}-\mathrm{S}\right.$, and $\mathrm{CL}_{\mathrm{N}}-\mathrm{S}$ ) yield the highest number of steadyflow hours.

2) Winter highs $\left(\mathrm{H}_{\mathrm{N}}\right.$ and $\left.\mathrm{H}_{\mathrm{E}}\right)$ exhibit a high number of steady hours at night.

3) PTs (PT-W, PT-M, and PT-D) have a high number of daytime steady hours.

4) Classes with weak synoptic forcing $\left(\mathrm{RST}_{\mathrm{E}}, \mathrm{RST}_{\mathrm{C}}\right.$, $\mathrm{H}_{\mathrm{C}}$, and $\mathrm{H}_{\mathrm{W}}$ ) have few steady hours (three of the eight representative hours).

Table 2 presents the average wind speed during the steady hours and complements the data of Table 1.

Four years of data were the minimum amount needed for this study. This fact was verified by calculating the frequency of events at each station under a sector width of two wind direction standard deviations as a function of the data size (i.e., one year's data, two years' data, and so on). The same frequency of events $(\sim 10 \%$ differences) was found from four years' and seven years' data.

In the following section, representative maps of the steady average surface wind field will be presented according to the above four categories. The similarity between steady surface wind fields from various hours 

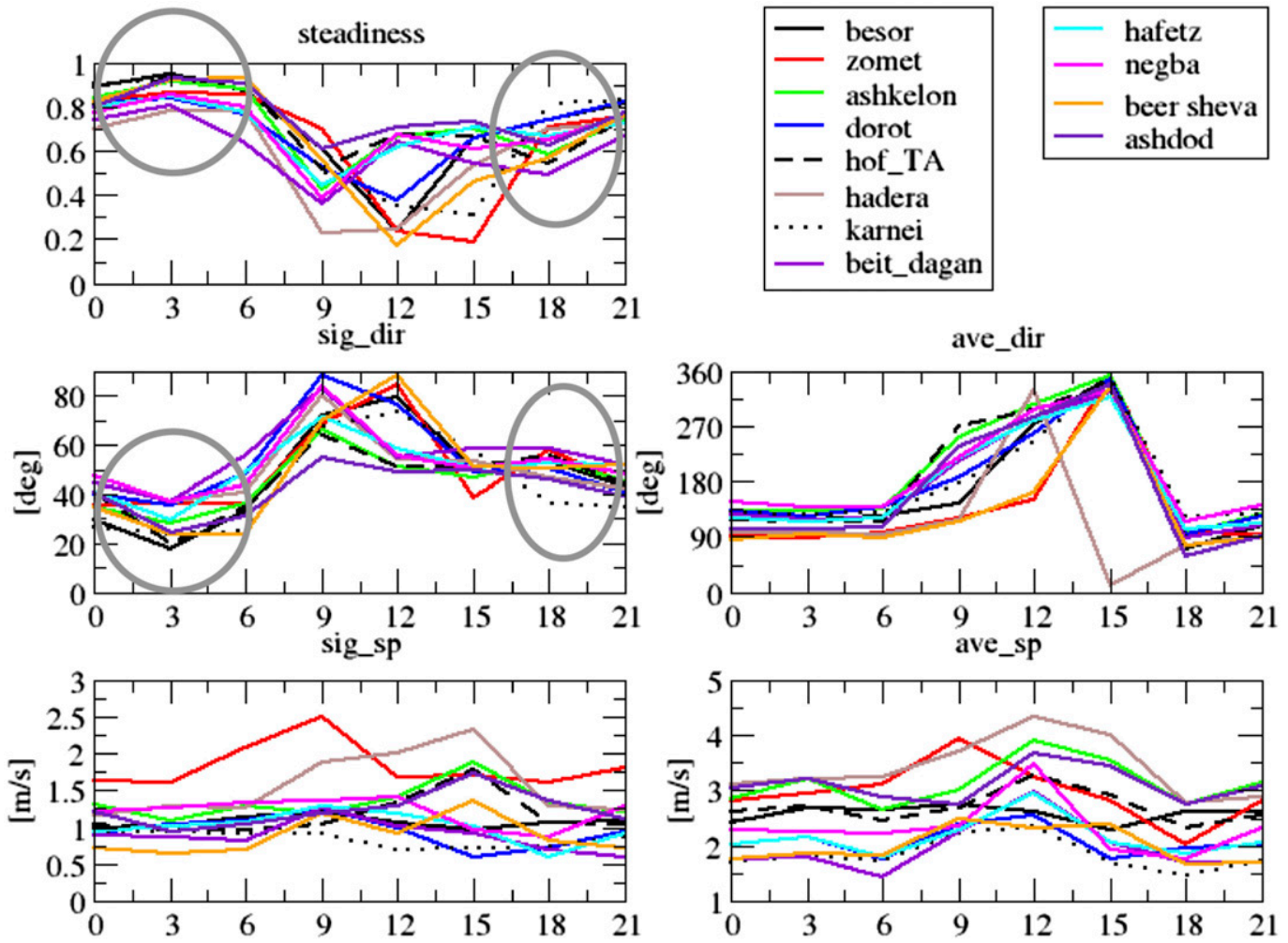

FIG. 5. For $\mathrm{H}_{\mathrm{E}}: S$, wind direction std dev (sig_dir), wind speed std dev (sig_sp), average wind direction (ave_ dir), and average wind speed (ave_sp). The hours at which high values of $S$ and low values of sig_dir were obtained are circled. Each station is represented by a different line in each panel. The horizontal axis represents the UTC time.

and/or classes will be indicated. The minimum, maximum, and average SD70 of the various stations at the steady hours will be summarized.

\section{d. Quantitative characterization of hourly surface wind fields as a function of synoptic class}

\section{1) WINTER LOWS}

The strongest synoptic effect is observed under $L_{E}-D$ and $\mathrm{CL}_{\mathrm{N}}-\mathrm{D}$. When these classes prevail, the land-breeze flow is completely erased. High steadiness characterizes each of the eight diurnal hours. Strong (maximum of $9 \mathrm{~m} \mathrm{~s}^{-1}$ ) southwest-west winds flow during the $\mathrm{L}_{\mathrm{E}}-\mathrm{D}$ events, and strong (maximum of $10 \mathrm{~m} \mathrm{~s}^{-1}$ ) south-southwest winds flow during the $\mathrm{CL}_{\mathrm{N}}-\mathrm{D}$ events. The average wind direction fields of these classes are very similar. A representative example from 1200 UTC under $\mathrm{CL}_{\mathrm{N}}$-D is given in Fig. 6.

During all of the hours studied, the flow along the coastline was stronger than the flow above the interior plain, with differences of $\sim 3 \mathrm{~m} \mathrm{~s}^{-1}$. As the wind flows over the terrain, it loses momentum because of friction. This phenomenon is also called the building-barrier effect.
Shallower lows do not block the easterly flow during the night. The shallow lows $\mathrm{L}_{\mathrm{W}}, \mathrm{L}_{\mathrm{E}}-\mathrm{S}$, and $\mathrm{CL}_{\mathrm{N}}-\mathrm{S}$ can be characterized only during the daytime. A lack of steady hours under shallow lows during the night also resulted from the high variability of pressure gradients under these classes.

The minimum, maximum, and average SD70 of the various stations at the steady-flow hours are displayed in Fig. 7. Under strong synoptic forcing $\left(\mathrm{L}_{\mathrm{E}}-\mathrm{D}\right.$ and $\mathrm{CL}_{\mathrm{N}}-\mathrm{D}$ ), smaller sector angles are obtained during daytime hours at 0900-1500 UTC (Fig. 7). Under weaker synoptic forcing $\left(\mathrm{Lw}, \mathrm{L}_{\mathrm{E}}-\mathrm{S}\right.$, and $\left.\mathrm{CL}_{\mathrm{N}}-\mathrm{S}\right)$, there is no significant difference between the widths during the daytime hours. At each relevant hour, the sector direction widths of the 12 stations vary by a factor of 2 [minimum $\left(50^{\circ}-70^{\circ}\right)$, maximum $\left(120^{\circ}-180^{\circ}\right)$, and average $\left.\left(90^{\circ}-120^{\circ}\right)\right]$.

\section{2) Winter Highs $\left(\mathrm{H}_{\mathrm{N}}\right.$ AND $\left.\mathrm{H}_{\mathrm{E}}\right)$}

For $\mathrm{H}_{\mathrm{E}}$ and $\mathrm{H}_{\mathrm{N}}$, the wind can be characterized for five-six of the eight representative hours. These synoptic classes (Fig. 2) enhance a flow with an easterly 
TABLE 1. The hours (UTC) at which steady flow was obtained as a function of synoptic class. Prominent average wind direction is indicated when steady flow is obtained.

\begin{tabular}{|c|c|c|c|c|c|c|c|c|}
\hline \multirow[b]{2}{*}{ Class } & \multicolumn{2}{|c|}{ Night } & \multicolumn{4}{|c|}{ Daytime } & \multicolumn{2}{|c|}{ Night } \\
\hline & 0000 & 0300 & 0600 & 0900 & 1200 & 1500 & 1800 & 2100 \\
\hline $\mathrm{L}_{\mathrm{E}}-\mathrm{D}$ & SW & SW & SW & SW & SW & $\mathrm{W}$ & SW, W & SW,W \\
\hline $\mathrm{CL}_{\mathrm{N}^{-}} \mathrm{D}$ & S & S & SSW & SW & SW & SW & SW & SW \\
\hline $\mathrm{L}_{\mathrm{W}}$ & & & SE & SW & SW & & & \\
\hline $\mathrm{L}_{\mathrm{E}}-\mathrm{S}$ & & & $\mathrm{S}$ & SW & $\mathrm{W}$ & W & & \\
\hline $\mathrm{CL}_{\mathrm{N}}-\mathrm{S}$ & & & & SW & W & $\mathrm{W}$ & & \\
\hline $\mathrm{H}_{\mathrm{E}}$ & SE, E & SE, E & SE, E & & & & $\mathrm{E}$ & E \\
\hline $\mathrm{H}_{\mathrm{N}}$ & SE, E & $\mathrm{SE}, \mathrm{E}$ & $\mathrm{E}$ & & & $\mathrm{N}$ & $\mathrm{NE}, \mathrm{E}$ & E \\
\hline PT-W & & SE & & W & NW & NW & NW & \\
\hline PT-M & & $\mathrm{S}, \mathrm{SE}$ & SW & W & $\mathrm{W}$ & NW & NW & \\
\hline PT-D & & S, SW & SW & W & $\mathrm{W}$ & $\mathrm{W}, \mathrm{NW}$ & & \\
\hline $\mathrm{RST}_{\mathrm{E}}$ & & $\mathrm{SE}$ & & & NW & NW & & \\
\hline $\mathrm{RST}_{\mathrm{C}}$ & $\mathrm{E}$ & $\mathrm{E}$ & E & & & & & E \\
\hline $\mathrm{H}_{\mathrm{W}}$ & & & & W & NW & NW & & \\
\hline $\mathrm{H}_{\mathrm{C}}$ & & $\mathrm{SE}$ & & & $\mathrm{W}$ & NW & & \\
\hline
\end{tabular}

component. Steady flow occurs during the night, when the mesoscale and the synoptic wind directions are similar.

Figure 8 displays representative wind fields for 0000 and 1800 UTC. During the daytime hours, no steady wind was obtained at 0900 or 1200 UTC. At 1500 UTC under $\mathrm{H}_{\mathrm{N}}$, steady flow from the north is obtained (Fig. 8). The average wind fields under $\mathrm{H}_{\mathrm{N}}$ and $\mathrm{H}_{\mathrm{E}}$ are similar (differences of $0.5 \mathrm{~m} \mathrm{~s}^{-1}$ between wind speeds may occur at the various stations in each hour).

Under winter highs during certain events, the synoptic forcing dictates north-east winds during the daytime (i.e., the sea breeze is canceled out by the synoptic wind). At other times, the synoptic forcing is not strong enough, and the sea-breeze effect is shown during the daytime. On the whole, there is no steady wind in the daytime hours.

Classes $\mathrm{H}_{\mathrm{N}}$ and $\mathrm{H}_{\mathrm{E}}$ are known to be associated with cold outbreaks with strong easterly to northeasterly winds over large parts of Israel, especially in the northern and eastern parts of the country (Ziv and Yair 1994; Saaroni et al. 1998). As a result of topographical differences, the results shown for the coastal plain poorly reflect conditions in these other regions.

The minimum, maximum, and average SD70 of the various stations at hours for which steady flow was obtained are summarized in Fig. 9. The minimal sector direction widths were obtained at 0300 UTC. The maximal widths were obtained at 1500 and 1800 UTC. The widths at the various stations vary by a factor of 2 for some hours, whereas for other hours (e.g., at 2100 UTC under both synoptic classes $\mathrm{H}_{\mathrm{E}}$ and $\mathrm{H}_{\mathrm{N}}$ and at
TABLE 2. The hours at which steady flow was obtained as a function of synoptic class. Prominent average wind speeds are indicated when steady flow is obtained.

\begin{tabular}{|c|c|c|c|c|c|c|c|c|}
\hline \multirow[b]{2}{*}{ Class } & \multicolumn{2}{|c|}{ Night } & \multicolumn{4}{|c|}{ Daytime } & \multicolumn{2}{|c|}{ Night } \\
\hline & 0000 & 0300 & 0600 & 0900 & 1200 & 1500 & 1800 & 2100 \\
\hline $\mathrm{L}_{\mathrm{E}}-\mathrm{D}$ & $5-2$ & $5-2$ & $6-2$ & $8-3$ & $8-3$ & $7-3$ & $7-2$ & $5-1$ \\
\hline $\mathrm{CL}_{\mathrm{N}^{-}} \mathrm{D}$ & $5-2$ & $5-2$ & $6-2$ & $9-3$ & $9-3$ & $9-3$ & $8-2$ & $8-2$ \\
\hline $\mathrm{L}_{\mathrm{W}}$ & & & $4-2$ & $6-3$ & $6-3$ & & & \\
\hline $\mathrm{L}_{\mathrm{E}}-\mathrm{S}$ & & & $4-2$ & $6-3$ & $6-3$ & $4-2$ & & \\
\hline $\mathrm{CL}_{\mathrm{N}^{-}} \mathrm{S}$ & & & & $5-3$ & $5-3$ & $5-3$ & & \\
\hline $\mathrm{H}_{\mathrm{E}}$ & $3-2$ & $3-2$ & $3-2$ & & & & $3-2$ & $3-2$ \\
\hline $\mathrm{H}_{\mathrm{N}}$ & $3-2$ & $3-2$ & $3-2$ & & & $5-2$ & $4-2$ & $3-2$ \\
\hline PT-W & & $3-1$ & & $5-3$ & $6-4$ & $6-3$ & $4-1$ & \\
\hline PT-M & & $3-1$ & $3-1$ & $5-2$ & $6-3$ & $5-3$ & $4-1$ & \\
\hline PT-D & & $5-2$ & $5-2$ & $6-3$ & $6-4$ & $6-3$ & & \\
\hline $\mathrm{RST}_{\mathrm{E}}$ & & $3-1$ & & & $5-2$ & $5-2$ & & \\
\hline $\mathrm{RST}_{\mathrm{C}}$ & $3-2$ & $3-2$ & $3-2$ & & & & & $3-2$ \\
\hline $\mathrm{H}_{\mathrm{W}}$ & & & & $4-2$ & $6-3$ & $6-3$ & & \\
\hline $\mathrm{H}_{\mathrm{C}}$ & & $4-1$ & & & $5-3$ & $5-2$ & & \\
\hline
\end{tabular}

$0300 \mathrm{UTC}$ under $\mathrm{H}_{\mathrm{N}}$ ), they are very similar (having a difference of $20^{\circ}-30^{\circ}$ ).

\section{3) Summer troughs (PT-W, PT-M, AND PT-D)}

High similarity among the average wind fields was found for the three PT classes. The effect of the pressure gradient on the mesoscale flow is noticeable, however.

The highest steadiness was obtained during the daytime, when the mesoscale (southwest-northwest) and the synoptic wind directions are similar. The strongest average wind speed during the daytime (0900 and

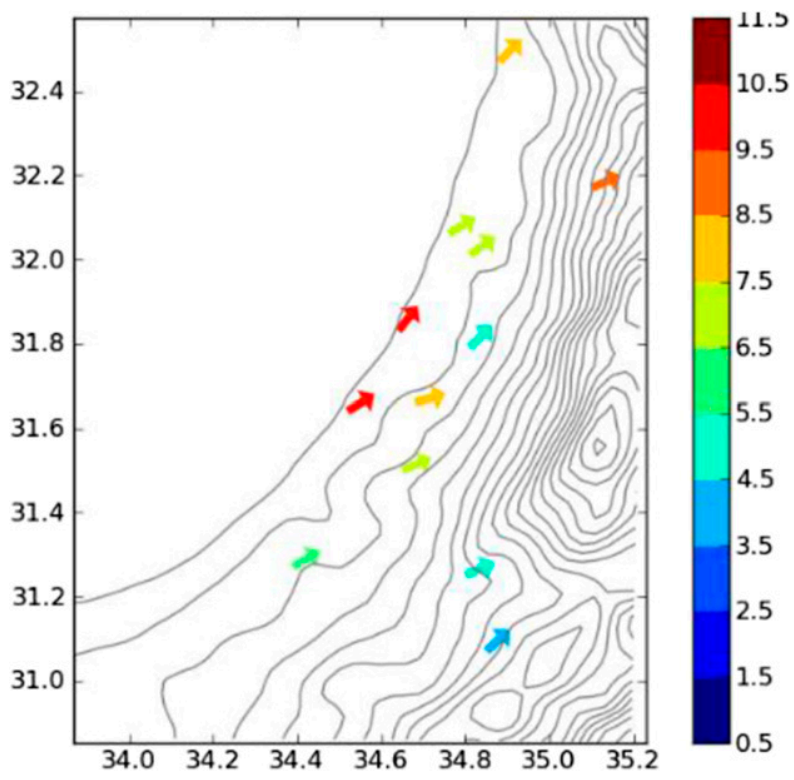

FIG. 6. $\mathrm{CL}_{\mathrm{N}}$-D at 1200 UTC. The color bar denotes wind speed $\left(\mathrm{m} \mathrm{s}^{-1}\right)$. 


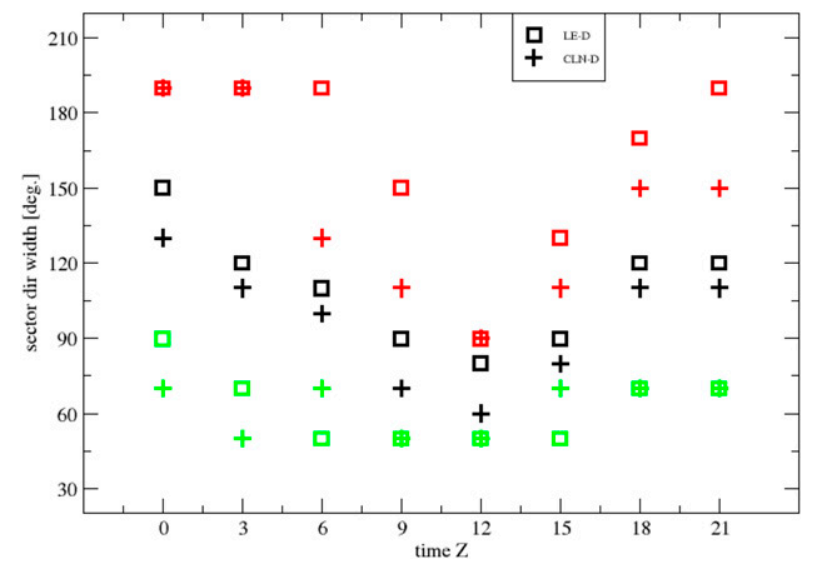

FIG. 7. The minimum (green), maximum (red), and average (black) sector direction widths (angles) within 70\% significance for the various stations during hours of steady wind flow under the influence of winter lows: $\mathrm{CL}_{\mathrm{N}}-\mathrm{D}$ (plus signs) and $\mathrm{L}_{\mathrm{E}}-\mathrm{D}$ (squares). The results were rounded to $10^{\circ}$.

1200 UTC) occurs under PT-D, which has the deepest pressure gradient; therefore, the westerly local flow is mostly enhanced. At 0900, 1200, and 1500 UTC, the wind speed under PT-D is stronger than the wind under PT-W and PT-M while the wind direction distribution is basically the same (Fig. 10 displays maps from 1200 UTC).

At 0300 UTC, the trough depth has a clear effect on the wind direction. Under PT-W, the flow is southeast. Under PT-M, there is a gradual change in the average wind direction as a function of distance from the shoreline. Southeast flow is obtained only along the shoreline; south-southeast winds flow along the lower mountain slopes (100-150 MSL), and south winds flow at the higher mountain slopes ( $300 \mathrm{~m}$ MSL). Under PT-D, no effect of land breeze or katabatic wind is obtained as the wind directions are south, southwest, and west. The wind speed is $1-2.5 \mathrm{~m} \mathrm{~s}^{-1}$ for the three classes.
At 0600 UTC, steady southwest flow occurs for PT-M and PT-D; in other words, the arrival of the sea breeze is enhanced by the deeper synoptic pressure gradient, and the average direction at all stations is southwest (Fig. 10 displays 0300 and 0600 UTC). At 1800 UTC, a steady northwest $1-3 \mathrm{~m} \mathrm{~s}^{-1}$ flow was obtained for PT-W and PT-M. PT-D steady flow was discounted because of lack of data (for this hour, fewer than 30 measurements were found). The $S$ values for PT-W and PT-M at 1800 UTC are lower than the $S$ values at 0900,1200, and 1500 UTC. Unlike Skibin and Hod (1979), this study does not find a regular flow for the three PT classes during the night (2100 and 0000 UTC).

The minimum, maximum, and average SD70 of the various stations at hours for which steady flow was obtained are displayed in Fig. 11. The smallest $\left(\leq 90^{\circ}\right)$ sector direction widths of the PT group were obtained during daytime hours. At 0300 UTC, under the influence of PT-W and PT-M, two stations (Beersheba and Karnei Shomron) were found with $S<0.4$ and wind direction standard deviations of $\sim 80^{\circ}$. Both stations are far $(\sim 50$ and $\sim 30 \mathrm{~km}$, respectively) from the coastline. At these places, the effect of breeze is reduced as a result of the distance from the coast and the mountain slopes.

4) WEAK SYNOPTIC FORCING $\left(\mathrm{RST}_{\mathrm{C}}, \mathrm{RST}_{\mathrm{E}}, \mathrm{H}_{\mathrm{C}}\right.$, AND $\mathrm{H}_{\mathrm{W}}$ )

The rest of the classes have a smaller effect on the prevailing flow because of a shallow pressure gradient. The wind variability increases and, therefore, only three-four of the eight representative hours can be characterized. These classes are $\mathrm{RST}_{\mathrm{C}}, \mathrm{RST}_{\mathrm{E}}, \mathrm{H}_{\mathrm{C}}$, and $\mathrm{H}_{\mathrm{W}}$.

Classes $\mathrm{H}_{\mathrm{W}}$ and PT-W have similar pressure gradient patterns; $\mathrm{H}_{\mathrm{W}}$ has the highest frequency of all classes

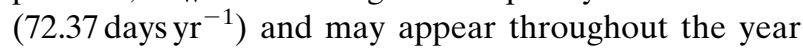
(including the summer). In the daytime hours (0900,
$15 Z$

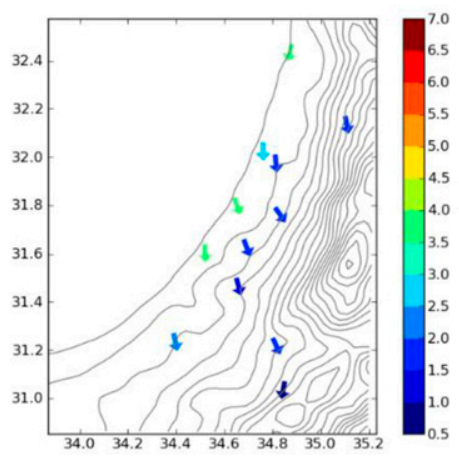

$18 Z$

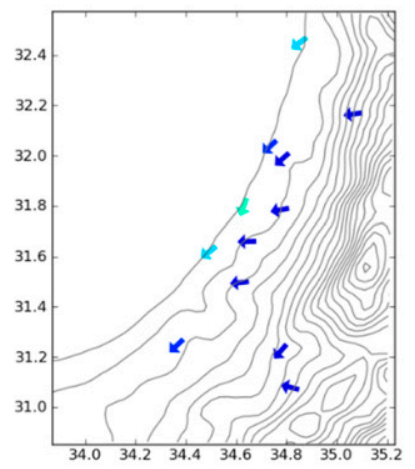

$0 \mathrm{Z}$

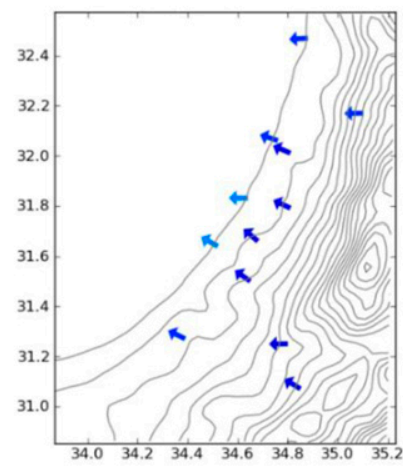

FIG. 8. The $\mathrm{H}_{\mathrm{N}}$ steady average surface winds at 1500,1800 , and $0000 \mathrm{UTC}$. The color bar denotes wind speed $\left(\mathrm{m} \mathrm{s}^{-1}\right)$. 


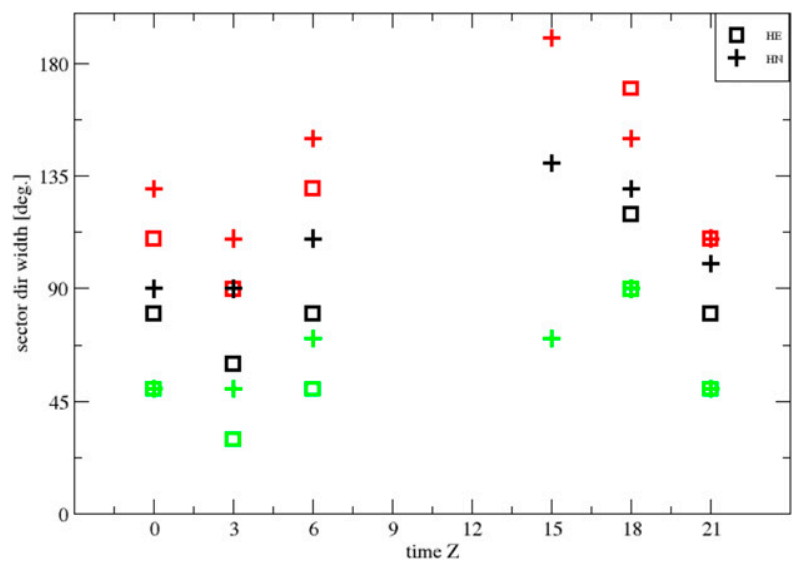

FIG. 9. As in Fig. 7, but under the influence of winter highs: $H_{N}$ (plus signs) and $\mathrm{H}_{\mathrm{E}}$ (squares).

1200, and 1500 UTC) steady west-northwest $1-5 \mathrm{~m} \mathrm{~s}^{-1}$ average winds were obtained. The average wind fields are very similar to the fields presented for PT-W.

The spatial distributions of the average wind direction under $\mathrm{RST}_{\mathrm{E}}$ and PT-W are very similar. Also, the maps of $\mathrm{H}_{\mathrm{C}}$ steady hours resemble the maps of $\mathrm{RST}_{\mathrm{E}}$ at 1200 UTC. At 0300 UTC, the average wind field is similar to the one presented for PT-M at 0300 UTC. The fact that three of eight representative hours can be characterized under the weak synoptic classes demonstrates the effect of the local factors, which introduce higher variability.

The minimum, maximum, and average SD70 of the various stations at hours in which steady flow was obtained are displayed in Figs. 12 and 13. Each synoptic class displays different behavior at different hours. The minimal sectors were found for $\mathrm{RST}_{\mathrm{C}}$ at 0000 and 0300 UTC $\left(70^{\circ}-110^{\circ}\right)$ and for $\mathrm{H}_{\mathrm{W}}$ at 1200 and 1500 UTC $\left(50^{\circ}-110^{\circ}\right)$.

To summarize the SD70s according to the various classes, the average (over 12 stations) SD70s are $50^{\circ}-150^{\circ}$. Smaller sector direction widths $\left(30^{\circ}-90^{\circ}\right)$ were obtained under the influence of $\mathrm{L}_{\mathrm{E}}-\mathrm{D}$ and $\mathrm{CL}_{\mathrm{N}}-\mathrm{D}$ (1200 UTC) PTs during daytime hours and $\mathrm{H}_{\mathrm{E}}$ and $\mathrm{H}_{\mathrm{N}}$ during the night hours (0300 UTC).

Classes $\mathrm{H}_{\mathrm{E}}, \mathrm{H}_{\mathrm{N}}, \mathrm{H}_{\mathrm{C}}, \mathrm{H}_{\mathrm{W}}$, and RSTs appear in the winter and the transition months. The analysis of these classes as based on the winter months (December-February) has
Hour UTC

PT-M

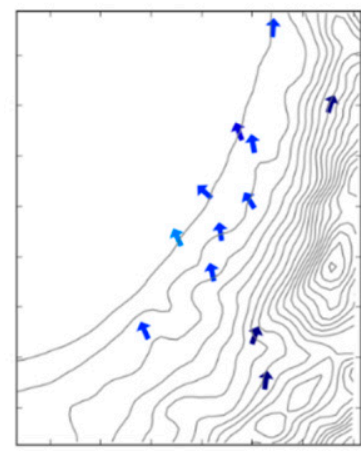

3
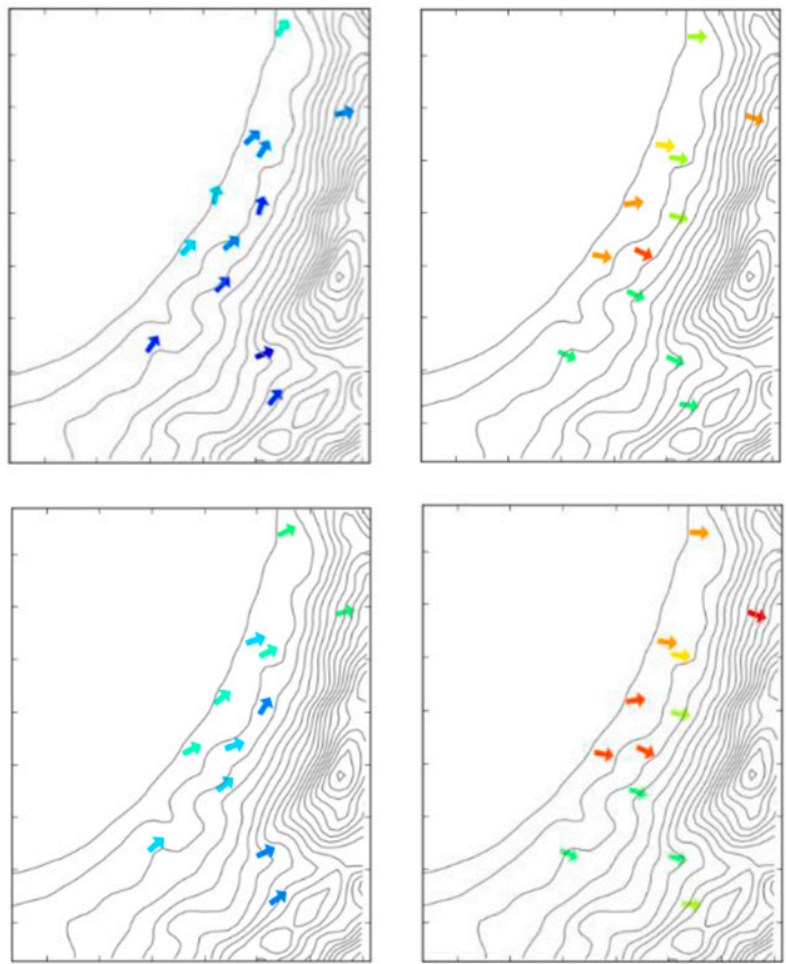

FIG. 10. PT-M and PT-D steady average surface winds at 0300, 0600, and 1200 UTC. The color bar denotes wind speed $\left(\mathrm{m} \mathrm{s}^{-1}\right)$. Maps of PT-W and PT-M at 0300 and 1200 UTC are very similar. 


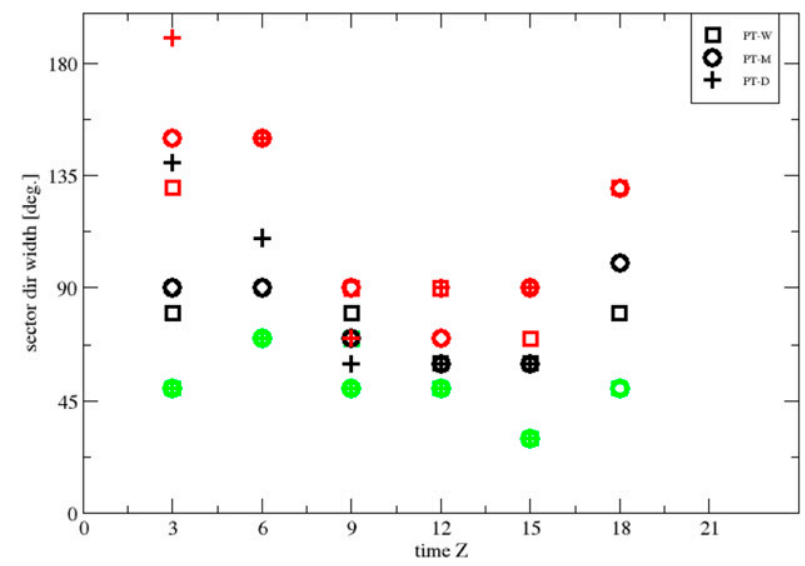

FIG. 11. As in Fig. 7, but under the influence of the PT group: PT-W (squares), PT-M (circles), and PT-D (plus signs).

shown similar results for $\mathrm{H}_{\mathrm{E}}, \mathrm{H}_{\mathrm{N}}, \mathrm{H}_{\mathrm{W}}$, and $\mathrm{RST}_{\mathrm{C}}$. Fewer than 30 events were obtained for $\mathrm{H}_{\mathrm{C}}$; therefore, no conclusion can be made. $\mathrm{RST}_{\mathrm{E}}$ has steady flow at 0300 and 0600 UTC (as opposed to 0300, 1200, and 1500 UTC according to the above analysis). In the case of $\mathrm{RST}_{\mathrm{E}}$, analysis according to seasons is required.

\section{Summary and conclusions}

This work verifies, according to statistical parameters, the ability of the synoptic classes defined by Alpert et al. (2004) at 1200 UTC to predict hourly surface wind regimes. The statistical results indicate that high steadiness of surface wind is achieved for a significant number of hours. To verify the characterization at 0000 UTC, two calculations are performed: the first according to the class defined at the previous 1200 UTC and the second according to the next 1200 UTC. The calculations showed similar results, except under $\mathrm{L}_{\mathrm{W}}$. Hence, the synoptic class is a predictor of the hourly surface winds during the year.

These results enable an automatic prediction of hourly surface winds according to synoptic class. They may aid in risk assessment, in statistical downscaling of seasonal or monthly winds, or in the prediction of pollutant dispersion according to wind regimes. Their potential in this regard was examined for the central and southern coastal and interior Israeli plains. It may be extended to other areas of Israel. To the best of our knowledge, no attempt has previously been made to quantitatively verify hourly wind regimes over Israel during the year. Beyond the qualitative knowledge that has been presented in previous literature and work, various meteorological applications demand quantitative characterization of wind regimes during the year.

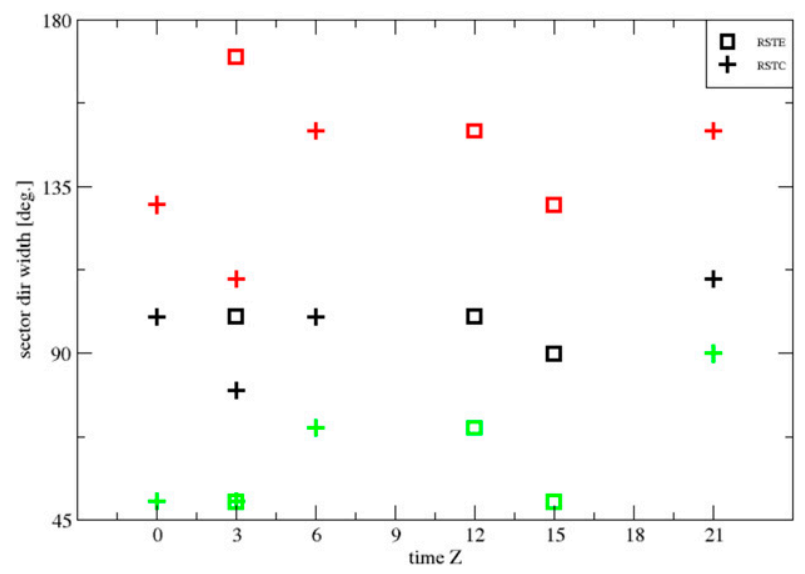

FIG. 12. As in Fig. 7, but under the influence of $\operatorname{RST}_{\mathrm{E}}$ (squares) and RSTc (plus signs).

This quantification may be improved by finding other predictors or by implementing other objective methods.

Typical prediction errors of surface wind direction and speed by meteorological models, such as WRF or MM5, are $30^{\circ}-70^{\circ}$ and $\sim 2 \mathrm{~m} \mathrm{~s}^{-1}$. Therefore, the errors of this synoptic approach and the theoretical models (without data assimilation) are similar (Berkovic and Feliks 2005).

The semiobjective classification (Alpert et al. 2004) is based on a predefined subjective set of synoptic classes that enables further objective characterization. The objective characterization is done by DA utilizing four meteorological fields at $1000 \mathrm{hPa}$ at $1200 \mathrm{UTC}(u, v$, geopotential height, and temperature). This automatic algorithm defines the synoptic class for any given day. Pressure maps with transitional synoptic character are assigned to the closest specific class. Similarity between pressure surfaces of different classes (e.g., PT-W and $\mathrm{L}_{\mathrm{W}}$, $\mathrm{H}_{\mathrm{E}}$ and $\mathrm{H}_{\mathrm{N}}$ or RSTs, or RSTs and winter Hs) may create

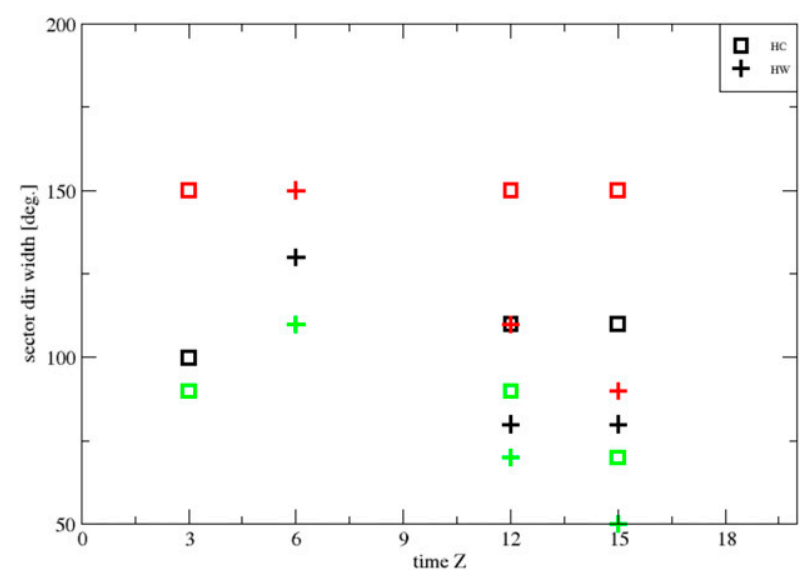

FIG. 13. As in Fig. 7, but for $\mathrm{H}_{\mathrm{C}}$ (squares) and $\mathrm{H}_{\mathrm{W}}$ (plus signs). 
ambiguity. The agreement between EM synoptic classifications was studied by Dayan et al. (2012). An uncertainty of $10 \%-30 \%$ per year was found in the characterization of the synoptic classes $\mathrm{H}_{\mathrm{W}}, \mathrm{PT}_{\mathrm{W}}$, and $\mathrm{RST}_{\mathrm{E}}$. When referring to events on a day-by-day basis during a 10-yr period, mismatches of over $50 \%$ were found for all of the classes except $\mathrm{CL}_{\mathrm{N}}-\mathrm{D}$ and $\mathrm{L}_{\mathrm{W}}$. Osetinsky (2006) checked the agreement between classifications according to two datasets-ECHAM4/OPYC3 and HadCM3 (see http://www.ametsoc.org/PubsAcronymList for definitions) - for the historical period of 1960-90. The GCMs were able to depict an average annual number of days for the large EM synoptic groups in the space of $1 \%-21 \%$ error as compared with the reanalysis.

The inspection of individual days during 1985 and comparison of the averages of the geopotential maps at the synoptic hours show that most of the events categorized under a certain synoptic class during the daytime preserve similar typical geopotential-height features. Different classes at hours other than 1200 UTC may occur; in most cases, however, the new class is related to the class at 1200 UTC, and the difference between adjacent classes may be less than the uncertainty of the classification.

When studying the wind histograms, low sensitivity was found to the exact definition of the synoptic class since similar wind histograms were obtained for closely related synoptic classes. Accordingly, while inspecting spatial distribution of the average wind at steady hours, similarities between the spatial distributions of similar classes were found. For example, at 0900, 1200, and 1500 UTC, steady west-northwest winds were found under $\mathrm{L}_{\mathrm{W}}$, $\mathrm{CL}_{\mathrm{N}}-\mathrm{S}, \mathrm{L}_{\mathrm{E}}-\mathrm{S}$, and $\mathrm{RST}_{\mathrm{E}}$, and steady southwest-west winds were found under PT-W, $\mathrm{H}_{\mathrm{W}}$, and $\mathrm{H}_{\mathrm{C}}$. Therefore, the average surface wind field is not highly sensitive to the exact definition of the synoptic class.

Acknowledgments. We thank Prof. Pinhas Alpert, Prof. Hadas Saaroni, Dr. Isabela Osetinsky, and Dr. Baruch Ziv for providing us with the synoptic classification data. We also thank Alpert, Ziv, Dr. Yizhak Feliks, and Dr. Dorita Rostkeir-Edelstein for helpful discussions. Thanks are given to the anonymous referees whose suggested comments helped to improve this article.

\section{REFERENCES}

Alpert, P., and B. Ziv, 1989: The Sharav Cyclone: Observations and some theoretical considerations. J. Geophys. Res., 94, 18 49518 514, doi:10.1029/JD094iD15p18495.

, I. Osetinsky, B. Ziv, and H. Shafir, 2004: Semi-objective classification for daily synoptic systems: Application to the eastern Mediterranean climate change. Int. J. Climatol., 24, 1001-1011, doi:10.1002/joc.1036.
Beaver, S., and A. Palazoglu, 2006: Cluster analysis of hourly wind measurements to reveal synoptic regimes affecting air quality. J. Appl. Meteor. Climatol, 45, 1710-1726, doi:10.1175/ JAM2437.1.

,,-- A. Singh, S. T. Soong, and S. Tanrikulu, 2010: Identification of weather patterns impacting 24-h average fine particulate matter pollution. Atmos. Environ., 44, 1761-1771, doi:10.1016/j.atmosenv.2010.02.001.

Berkovic, S., and Y. Feliks, 2005: The sea and land breeze simulation with data assimilation in urban area by the MM5 model. Proc. World Weather Research Programme's Symp. on Nowcasting and Very Short Range Forecasting, Toulouse, France, WWRP, 6.7. [Available online at http://www.meteo.fr/ cic/wsn05/resumes_longs/6.07-8.pdf.]

Conil, S., and A. Hall, 2006: Local regimes of atmospheric variability: A case study of southern California. J. Climate, 19 , 4308-4325, doi:10.1175/JCLI3837.1.

Dayan, U., A. Tubi, and I. Levy, 2012: On the importance of synoptic classification methods with respect to environmental phenomena. Int. J. Climatol., 32, 681-694, doi:10.1002/joc.2297.

Doron, E., and J. Neumann, 1977: Land and mountain breezes with special attention to Israel's Mediterranean coastal plain. Isr. Meteor. Res. Pap., 1, 109-122.

Ganor, E., I. Osetinsky, A. Stupp, and P. Alpert, 2010: Increasing trend of African dust, over 49 years, in the eastern Mediterranean. J. Geophys. Res., 115, D07201, doi:10.1029/ 2009JD012500.

Gilliam, R. C., S. Raman, D. Dutta, and S. Niyogi, 2004: Observational and numerical study on the influence of large-scale flow direction and coastline shape on sea-breeze evolution. Bound.-Layer Meteor., 111, 275-300, doi:10.1023/ B:BOUN.0000016494.99539.5a.

Goldreich, Y., 2003: The Climate of Israel: Observation, Research and Application. Springer, $270 \mathrm{pp}$.

_ L. M. Druyan, and H. Berger, 1986: The interaction of valley/ mountain winds with a diurnally veering sea/land breeze. J. Climatol., 6, 551-561, doi:10.1002/joc.3370060508.

Guardans, R., and I. Palomino, 1995: Description of wind field dynamic patterns in a valley and their relation to mesoscale and synoptic-scale meteorological situations. J. Appl. Meteor. Climatol., 34, 49-67, doi:10.1175/1520-0450-34.1.49.

Holton, J. R., 2004: An Introduction to Dynamic Meteorology. Academic Press, 535 pp.

Jimenez, P. A., J. F. Gonzalez-Rouco, J. P. Montavez, E. GarciaBustamante, and J. Navarro, 2009: Climatology of wind patterns in the northeast of the Iberian Peninsula. Int. J. Climatol., 29, 501-525, doi:10.1002/joc.1705.

Kallos, G., P. Kassomenos, and R. A. Pielke, 1993: Synoptic and mesoscale weather conditions during air pollution episodes in Athens, Greece. Bound.-Layer Meteor, 62, 163-184, doi:10.1007/ BF00705553.

Kalnay, E., and Coauthors, 1996: The NCEP/NCAR 40-Year Reanalysis Project. Bull. Amer. Meteor. Soc., 77, 437-470, doi:10.1175/1520-0477(1996)077<0437:TNYRP>2.0.CO;2.

Kassomenos, P. H., A. Flocas, S. Lykoudis, and M. Petrakis, 1998: Analysis of mesoscale patterns in relation to synoptic conditions over an urban Mediterranean basin. Theor. Appl. Climatol., 59, 215-229, doi:10.1007/s007040050025.

Levy, I., U. Dayan, and Y. Mahrer, 2008: A five-year study of coastal recirculation and its effect on air pollutants over the east Mediterranean region. J. Geophys. Res., 113, D16121, doi:10.1029/ 2007JD009529. 
, and - 2010: Differing atmospheric scales of motion and their impact on air pollutants. Int. J. Climatol., 30, 612619, doi:10.1002/joc.1905.

Lionello, P., 2012: The Climate of the Mediterranean Region: From the Past to the Future. Elsevier, 592 pp.

Maheras, P., I. Patrikas, T. Karacostas, and C. Anagnostopoulou, 2000: Automatic classification of circulation types in Greece: Methodology, description, frequency, variability and trend analysis. Theor. Appl. Climatol., 67, 205-223, doi:10.1007/ s007040070010.

Namboodiri, K. V. S., P. K. Dileep, and K. Mammen, 2012: Wind steadiness up to $35 \mathrm{~km}$ and its variability before the southwest monsoon onset and the withdrawal. Mausam, 63, 275-282.

Ngan, F., and D. Byun, 2011: Classification of weather patterns and associated trajectories of high-ozone episodes in the HoustonGalveston-Brazoria area during the 2005/06 TexAQS-II. J. Appl. Meteor. Climatol., 50, 485-499, doi:10.1175/ 2010JAMC2483.1.

Nigro, M. A., and J. J. Cassano, 2014: Identification of surface wind patterns over the Ross Ice Shelf, Antarctica, using self-organizing maps. Mon. Wea. Rev., 142, 2361-2378, doi:10.1175/ MWR-D-13-00382.1.

Osetinsky, I., 2006: Climate changes over the E. MediterraneanA synoptic systems classification approach. Ph.D. thesis, Tel Aviv University, 153 pp. [Available online at http://primage. tau.ac.il/libraries/theses/exeng/free/2079562.pdf.]

Pakalapati, S., S. Beaver, J. A. Romagnoli, and A. Palazoglu, 2009: Sequencing diurnal air flow patterns for ozone exposure assessment around Houston, Texas. Atmos. Environ., 43, 715723, doi:10.1016/j.atmosenv.2008.09.054.

Pearce, J. L., J. Beringer, N. Nicholls, R. J. Hyndman, P. Uotila, and N. J. Tapper, 2011: Investigating the influence of synopticscale meteorology on air quality using self-organizing maps and generalized additive modelling. Atmos. Environ., 45, 128 136, doi:10.1016/j.atmosenv.2010.09.032.

Poupkou, A., P. Zanis, P. Nastos, D. Papanastasiou, D. Melas, K. Tourpali, and C. Zerefos, 2011: Present climate trend analysis of the etesian winds in the Aegean Sea. Theor. Appl. Climatol., 106, 459-472, doi:10.1007/s00704-011-0443-7.
Rostkier-Edelstein, D., P. Kunin, T. M. Hopson, Y. Liu, and A. Givati, 2015: Statistical downscaling of seasonal precipitation in Israel. Int. J. Climatol., 36, 590-606, doi:10.1002/joc.4368.

Saaroni, H., B. Ziv, A. Bitan, and P. Alpert, 1998: Easterly wind storms over Israel. Theor. Appl. Climatol., 59, 61-77, doi:10.1007/s007040050013.

- , H. Halfon, B. Ziv, P. Alpert, and H. Kutiel, 2010a: Links between the rainfall regime in Israel and location and intensity of Cyprus lows. Int. J. Climatol., 30, 1014-1025, doi:10.1002/ joc. 1912.

_, T. Uman, and B. Ziv, 2010b: Does a synoptic classification indicate the $\mathrm{NO}_{x}$ pollution potential? The case of the metropolitan area of Tel Aviv, Israel. Water Air Soil Pollut., 207, 139-155, doi:10.1007/s11270-009-0125-6.

Skibin, D., and A. Hod, 1979: Subjective analysis of mesoscale flow patterns in northern Israel. J. Appl. Meteor., 18, 329-338, doi:10.1175/1520-0450(1979)018<0329:SAOMFP > 2.0.CO;2.

Tsvieli, Y., and A. Zangvil, 2007: Synoptic climatological analysis of Red Sea trough and non-Red Sea trough rain situations over Israel. Adv. Geosci., 12, 137-143, doi:10.5194/ adgeo-12-137-2007.

Tyrlis, E., and J. Lelieveld, 2013: Climatology and dynamics of the summer etesian winds over the eastern Mediterranean. J. Atmos. Sci., 70, 3374-3396, doi:10.1175/JAS-D-13-035.1.

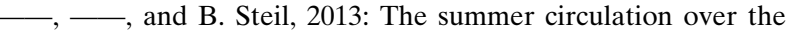
eastern Mediterranean and the Middle East: Influence of the South Asian monsoon. Climate Dyn., 40, 1103-1123, doi:10.1007/s00382-012-1528-4

Yamartino, R. J., 1984: A comparison of several "single-pass" estimators of the standard deviation of wind direction. J. Climate Appl. Meteor., 23, 1362-1366, doi:10.1175/1520-0450(1984)023<1362: ACOSPE $>2.0 . C O ; 2$.

Zhong, S., and E. S. Takle, 1993: The effects of large-scale winds on sea-land-breeze circulations in an area of complex coastal heating. J. Appl. Meteor., 32, 1181-1195, doi:10.1175/ 1520-0450(1993)032<1181:TEOLSW > 2.0.CO;2.

Ziv, B., and Y. Yair, 1994: An Introduction to Meteorology (in Hebrew). Open University of Israel, $411 \mathrm{pp}$.

, H. Saaroni, and P. Alpert, 2004: The factors governing the summer regime of the eastern Mediterranean. Int. J. Climatol., 24, 1859-1871, doi:10.1002/joc.1113. 